\title{
The effect of antenatal depression on birth weight among newborns in South Gondar zone, Northwest Ethiopia: a population- based prospective cohort study
}

Getnet Mihretie Beyene ${ }^{1,2^{*}}$ (D) Telake Azale ${ }^{3}$, Kassahun Alemu Gelaye ${ }^{2}$ and Tadesse Awoke Ayele ${ }^{2}$

\begin{abstract}
Background: There is a high prevalence of antenatal depression and low birth weight (LBW) $(<2.5 \mathrm{~kg})$ in Ethiopia. Prior evidence revealed that the association between antenatal depression and LBW in high- and low-income countries is conflicting. The effect of antenatal depression on birth weight is under-researched in Ethiopia. We aimed to examine the independent effect of antenatal depression on newborn birth weight in an urban community in Northwest Ethiopia.

Methods: A total of 970 pregnant women were screened for antenatal depression in their second and third trimester of pregnancy through the use of the Edinburgh Postnatal Depression Scale (EPDS). A logistic regression model was used to adjust confounders and determine associations between antenatal depression and low birth weight. Information was collected on the birth weight of newborns and mother's socio-demographic, anthropometric, obstetric, clinical, psychosocial, and behavioral factors.

Results: The cumulative incidence of LBW was found to be $27.76 \%$. The cumulative incidence of LBW in those born from depressed pregnant women was $40 \%$ as compared to $21 \%$ in none depressed. While considering all other variables constant, mothers who had antenatal depression were $2.51(\mathrm{COR}=2.51$ (95 Cl: 1.87, 3.37)) more likely to have a child with low birth weight. After adjusting for potential confounders, antenatal depression in the second and third trimester of pregnancy $(A O R=1.92(95 \% \mathrm{Cl}: 1.31,2.81))$ remained significantly associated with LBW. MidUpper Arm Circumference (MUAC) $\leq 21$, lack of ANC follow up, and preterm births were also associated with LBW.

Conclusion: This study showed that antenatal depression during the second and third trimester of pregnancy is associated with LBW of newborns and replicates results found in high-income countries. Linking early screening, detection, and treatment of antenatal depression into routine antenatal care could be essential to improve pregnancy outcomes.
\end{abstract}

Keywords: Pregnancy, Depression, Antenatal depression, Birth weight, Ethiopia

\footnotetext{
* Correspondence: getnet.mihretie@gmail.com

'Department of Psychiatry, College of Health Sciences, Debre Tabor University, Debre Tabor, Ethiopia

${ }^{2}$ Department of Epidemiology and Biostatistics, College of Medicine and Health Sciences, University of Gondar, Gondar, Ethiopia

Full list of author information is available at the end of the article
}

(c) The Author(s). 2021 Open Access This article is licensed under a Creative Commons Attribution 4.0 International License, which permits use, sharing, adaptation, distribution and reproduction in any medium or format, as long as you give appropriate credit to the original author(s) and the source, provide a link to the Creative Commons licence, and indicate if changes were made. The images or other third party material in this article are included in the article's Creative Commons licence, unless indicated otherwise in a credit line to the material. If material is not included in the article's Creative Commons licence and your intended use is not permitted by statutory regulation or exceeds the permitted use, you will need to obtain permission directly from the copyright holder. To view a copy of this licence, visit http://creativecommons.org/licenses/by/4.0/. The Creative Commons Public Domain Dedication waiver (http://creativecommons.org/publicdomain/zero/1.0/) applies to the data made available in this article, unless otherwise stated in a credit line to the data. 


\section{Background}

The antenatal period is typically referred to as the time from the starting of pregnancy and ends with the onset of labor [1]. The scientific literature indicates that this is a time when a pregnant woman is vulnerable to affective disorders; specifically, these are common in mid and late trimesters [2, 3]. During late pregnancy, fear of childbirth and dysfunctional coping style is associated with emotional disturbance [4]. Pregnancy can intensify the susceptibility to the mental, physical, and psychological health of women and their fetuses [5]. Among mental health problems that occurred during pregnancy, depression is the most prevalent psychiatric disorder affecting pregnant women $[3,6]$.

The prevalence rate of depression during pregnancy has been significantly higher in developing countries than in developed ones [7]. There is increasing evidence that the rate of depression during pregnancy is two to three times higher in Low and Middle-Income Countries (LMICs) as compared to High-Income Countries (HICs) [8]. In Ethiopia's context, the prevalence of antenatal depression varies across different parts of the region; it ranges between $11.8 \%$ [9] and 31.2\% [10].

Depressive symptoms during pregnancy may have devastating effects, not only for the women but also for the birth outcome and family [11]. Pregnant women with depressive symptoms experience social dysfunction, are more emotionally withdrawn, express excessive concern about the pregnancy and their ability to parent [12]. Furthermore, likely of using tobacco, alcohol, drugs, and less likely to have adequate prenatal care are known to affect the fetus, the baby, and the mother herself [13-16]. Besides this pregnant women with depression may also develop increased risk of preeclampsia [17], diabetes [18], and operative deliveries [19]. Reports from LMICs showed that antenatal depression significantly increased the risk of prolonged labor [20].

There is evidence that indicates antenatal depression also has numerous adverse effects on neonatal health outcomes [21-23]. Among these adverse effects, low birth weight is the prominent cause of neonatal, infant, childhood morbidity, mortality, and developmental impairments worldwide [24, 25].

Currently, different organizations are working to reduce LBW globally by $30 \%$ by the year 2025 [26]. Despite this activity, more than 20 million infants were born with LBW in 2015, almost half of them in Southern Asia and one quarter in Africa, with the majority born in Eastern and Western Africa [27]. Similarly, in Ethiopia, globally recommended strategies have been implemented. However, according to Ethiopia demographic and health Survey report, LBW is increasing from $11 \%$ in 2011 [28] to $13 \%$ in 2016 [29], and a variety of studies were conducted to estimate the prevalence of LBW in
Ethiopia; ranges from $6.1 \%$ [30] to $29.1 \%$ [31]. There is spatial clustering of LBW in Ethiopia, specifically in the Amhara region [32], which is the most cause of early neonatal deaths $[33,34]$ and accounted for the highest case related neonatal mortality [35].

Studies from Australia [36], Finland [37], USA [23], and systematic review and a meta-analysis [38, 39] have reported that antenatal depression is associated with LBW. Few studies from LMICs such as Pakistan [21], India [40], China [41] and Malaysia [42] pointed out that antenatal depression was associated with an increased risk of LBW. In the Ethiopian context, there are only two studies one by Hanlon C.et al. [43] and the other by Fekadu DA et al. [44] that stated the effect of antenatal depression on birth weight, despite the high prevalence of antenatal depression $[45,46]$. Of these, one is not specific to depression; instead, it stated the impact of antenatal common mental disorders upon perinatal outcomes [43].

We thought that antenatal depressive symptoms are independent of other factors that reduce the birth weight due to several behavioral features associated with depression: loss of motivation and interest in everyday activities [47],decreased healthy nutrition and increased unhealthy food [48], tendency to consume fewer macronutrients [49], inadequate maternal dietary intake [50] and elevated level of cortisol hormone [51] affect fetal growth and consequently lead to LBW.

Different study findings showed that improving psychosocial health facilities for antenatally depressed women in low-income communities can lead to improved neonatal outcomes [52]. Despite the improvement in health care services in Ethiopia, the status of LBW increases from time to time [28, 29]. This might be due to the recently reported high frequency of antenatal depression reported in a different region of Ethiopia. In this prospective community-based study, we addressed this shortcoming by examining the association between antenatal depression during the second and the third trimester of pregnancy and LBW neonates among urban women in Ethiopia.

\section{Methods}

\section{Study design and settings}

We conducted a community-based prospective cohort study at Debre Tabor and Woreta towns, which are situated in the South Gondar zone from June 2019 to March 2019 in the Northwest, Ethiopia.

According to the South Gondar zonal catchment profile, the estimated total population of Debre Tabor town was 84,382 , of which 40,753 are females. While Woreta town has an estimated population of 41,668 , of which 20,507 are females. About 2844 women at Debre Tabor and 1404 women in Woreta towns were estimated to be 
pregnant per year [53]. In these towns, there were one government-operated referral hospital, five health centers, and ten private health institutions providing health services during the data collection period.

Health extension workers (HEWs) are responsible for performing prevention and promotion activities, identifying and monitoring pregnant mothers, and maintaining up-to-date maternal records in each Kebele which is the lowest administrative unit or village in Ethiopia. The previous year's report of the district health office showed that the proportion of pregnant women who were using antenatal care services at Debre Tabor and Woreta towns were estimated to be 75 and $64 \%$, respectively [53]. Source population were all live new born from cohort pregnant women recruited at base line at Debre Tabor and Woreta towns and all live new born from cohort pregnant women at Debre Tabor and Woreta towns during the study period were used as study population.

\section{Sample size}

The sample size was estimated using the double population formula, with the exposed and non-exposed ratio of 1:2 (exposed are those who are depressed and nonexposed are those who are not depressed). A 95\% level of confidence, $80 \%$ power and $10 \%$ non-response rate were considered.

\section{Cohort recruitment and eligibility}

All eligible and consenting women were recruited into the cohort. Pregnant women who were in their 2nd and $3^{\text {rd }}$ trimesters, and living in Debre Tabor and Woreta Towns for at least the preceding 6 months, and without any cognitive or hearing impairment during the study period were included. Health Extension Workers (HEWs) identify all pregnant women in their respective kebeles and register them based on the criteria mentioned above.

The data collectors (HEWs) conducted an interview through the home-to-home visits to identify pregnant women who were willing to participate in this study and declared untraceable after three recruiting visits had been unsuccessful. All pregnant women who were aware of their pregnancy and fulfilled the criteria from June 2019 to October 2019 were included in the study. A total of 970 eligible women were identified and prospectively followed up until March 2020. Potentially newborn is eligible if they were born alive.

\section{Data quality management}

Twenty experienced data collectors and two supervisors participated in the data collection process after 2 days of training. All the data collectors were recruited from each kebeles. The data collectors had a diploma and a degree in nursing. The supervisors had MSc educational level.
The training was aimed to help trainees understand the contents of the questionnaire, objectives, and ethical issues relevant to the study. The ongoing quality of the data was closely monitored by supervisors and the authors of the study on a weekly face to face meeting and telephone communications.

\section{Measurement \\ Primary exposure}

Antenatal depression was the primary exposure variable, which was assessed using the Edinburgh Postnatal Depression Scale (EPDS). The EPDS has a sensitivity and specificity of 78.9 and $75.3 \%$, respectively, from a validation study in Ethiopia [54]. It includes ten items with a Likert scale of responses scored from 0 to 3 to a maximum score of 30 , which was then coded as a categorical variable score $\geq 12$ as indicative of the probable depressive disorder.

EPDS is a preferable scale than other depression scales to screen depression during pregnancy because it removes the physical symptoms of depression associated with pregnancy [55].

\section{Outcome variables}

The primary outcome variable was birth weight. Birth weight was categorized as low birth weight $(<2500 \mathrm{~g})$ and normal birth weight $(\geq 2500 \mathrm{~g})$. The weight measurement of the babies was taken from a written paper (birth notification paper) with baby's weight given from health facilities. If a mother did not have the paper the data collectors take the information from facilities records within $24 \mathrm{~h}$ of delivery. If the birth weight was not measured at health facilities, HEWs measured birth weight using Salter scales to the nearest $0.1 \mathrm{~g}$.

\section{Potential confounding variables}

The most common potential confounding factors were considered in the present study based on previous literature such as threatening life events, social support, intimate partner violence, any chronic medical condition, ANC visit, history of complications current pregnancy, preterm delivery, history of alcohol consumption, malnutrition and socio-demographic and economic variables, including marital status, wealth index and level of education were also assessed.

Experiences of stressful life events during the 6 months before assessment were assessed using the List of Threatening Experiences (LTE). The scale contains twelve items and includes questions of death, illness, conflicts, and loss of property [56]. The presence of stressful life events explained by experienced one or more stressful life events in the last 6 months. The testretest reliability of the LTE was good, with a Kappa of $0.61-0.87$ and very good predictive validity [57]. 
The Oslo Social Support Scale (OSSS-3) [58] was used to measure maternal social support during pregnancy. The level of social support is classified as "poor support" 3-8, "moderate support" 9-11, and "strong support," 12-14 scores. The OSSS-3 consists of three items assessing the number of close intimate, perceived level of concern from others, and perceived ease of getting helps from neighbors. The OSSS-3 has good convergent and predictive validity [59]. Both the LTE12 and the OSSS- 3 have been used in a populationlevel study in Ethiopia [60].

We identified women who were exposed to Intimate Partner Violence (IPV) during pregnancy by asking pregnant women three questions on emotional IPV, physical IPV, and sexual IPV. The presence of IPV was ascertained by the presence of at least one type of IPV [61].

The history of physician-diagnosed chronic medical conditions, including cardiac disease, hypertension was counted for each woman and recorded as "No" for those without any chronic medical conditions and "Yes" otherwise. The numbers of ANC visits were recorded. Preterm was categorized as Yes if babies were born alive before 37 weeks of pregnancy or No if otherwise. Stillbirth was considered as the death of the fetus after 20 completed weeks of gestation [62]. Gestational age was calculated based on the last normal menstrual period. However, gestational age was measured from ultrasound scan measurement, for women who were found to be unsure date of last normal menstrual period by linking them to the nearest health facility.

History of depression and family history of depression was assessed by using "case vignette". History of current pregnancy complications: anemia, hypertension, edema, antepartum haemorrhage (APH) were counted for each woman and recorded as "yes/no." Alcohol use was assessed using a four-item scale, the Fast Alcohol Screening Test (FAST) [63], which ranges from 0 to 16 . Hazardous drinking refers to a score of three or more in a FAST scale [63].

The anthropometric indicators of the pregnant women used in the study were MUAC (in $\mathrm{cm}$ ) to the nearest of $0.1 \mathrm{~cm}$. MUAC is seen as a proxy indicator of the nutritional status of the women as well as it is relatively stable throughout pregnancy [64]; it is a validated and recommended measurement, with a cutoff score of $18-22 \mathrm{~cm}$ as underweight, and $22.1-31$ $\mathrm{cm}$ as normal [65]. The wealth index was calculated using principal component analysis and categorized into three levels as High, Middle, and Low groups during ranking from the highest (usually the wealthiest) to the lowest scores (usually the poorest).

\section{Analysis strategy}

We used Stata software (version 14) for analysis. We run descriptive statistics and correlation of all the quantitative study variables. Percentage values, with their corresponding 95\% confidence intervals (CIs), were used to summarize categorical variables. We used the odds ratio to measure the effect of antenatal depression on birth weight. We carried out Univariate logistic regression analyses for each risk factor to identify possible predictors associated with LBW. Variables with a $p<0.2$ in the bivariate analyses were included in the multivariable logistic regression. The difference was deemed to be significant if $p<0.05$. The total number of loss to follow up was $32(3.2 \%)$. We also used a complete case analysis as it was suggested that less than $5 \%$ lost to follow up was with little concern $[66,67]$.

\section{Ethical considerations}

We obtained ethical approval from the Amhara region public health institute and the research ethics review committee of the University of Gondar. Before we want to collect the data participation information sheet was read for all participants and we obtained informed consent for all participants. Initially, pregnant women's $\geq$ 2nd trimester was registered by health extension workers in all towns through home to home visits. Then, the sample size was allocated proportionally based on the actual number of registered pregnant women's after having the list. Those women who were expressing suicidal ideation were referred to Debre Tabor referral Hospital Psychiatry unit for further diagnosis and appropriate management. The decision to refer was made by the project co-coordinator (GM) based on a review of all women who were expressing suicidal ideation.

\section{Results}

A flow chart of recruited women and the main outcomes is presented in Fig. 1. In total, 970 pregnant women were eligible to participate; 32 women (3.3\%) were excluded during follow-up period from the sample for reasons that refusal to participate and moving from the area. Five pregnant women gave stillbirth. Finally, 933 women were included in the analysis, with a response rate of $96.2 \%$.

The gestational age range from 16 to 34 , with average gestation at recruitment was 25.6 weeks. Birth weight range was $1.8 \mathrm{~kg}$ to $3.9 \mathrm{~kg}$, and with a mean birth weight $(2.71 \pm 0.45 \mathrm{SD})$. Two hundred and fifty-nine babies $(27.76 \%)$ had a low birth weight i.e. $<2500 \mathrm{~g}$.

\section{Socio-demographic characteristics of the study participants}

According to chi square test, none of socio-demographics factors was significant. Out of 933 participants, 401(43\%) were between the ages of $25-29$ years. The mean $( \pm \mathrm{SD})$ maternal age was $27.1 \pm 4.8 \mathrm{y}$. The data revealed that most of the participants were composed of young adults with 


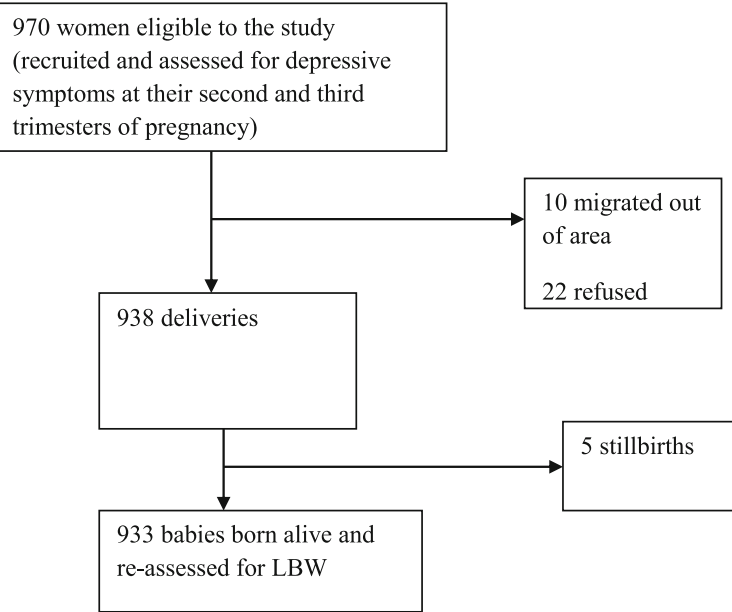

Fig. 1 Flow chart of recruited pregnant women and outcome of birth weight

793(85\%) formally educated, predominately at Diploma and above in educational level. The majority of women 864(92.6\%) were Orthodox Christian by religion, and $624(92 \%)$ of the women were married (Table 1).

\section{Obstetric and clinical characteristics of the respondents}

Regarding the obstetric and clinical characteristics of the sample, approximately 533(57\%) were found in the second trimester, and the remaining was in the third trimester, $109(12 \%)$ had a history of current pregnancy complication, $67(7 \%)$ had a chronic disease, 148(16\%) experienced acute malnutrition (MUAC less than or equal to 21$), 91(10 \%)$ experienced spontaneous preterm births, $6(0.64 \%)$ had twins delivery. Of the respondents, $374(40 \%)$ were primi-gravida with a mean of 1.9 per woman (Table 2).

\section{Psychosocial and behavioral characteristics of the study participants}

Out of 933 participants, approximately 489(52.41\%) experienced intimate partner violence, $416(45 \%)$ had poor social support, and 206 (22\%) had hazardous level use of alcohol (Table 3).

\section{Factors associated with low birth weight}

Bivariate regression analysis showed a significant positive association between LBW and antenatal depressive symptoms, a complication of current pregnancy, not ANC follow up, life-threatening events, intimate partner violence, $M U A C \leq 21$, preterm, and unplanned pregnancy. Multiple logistic regression analyses showed that, after adjustment for covariates, women with antenatal depression symptoms (AOR = 1.92 (95\% CI: 1.31, 2.81)) were almost twice more likely to give LBW babies than women without antenatal depression symptoms. Other positively associated factors were babies born before 37 weeks (preterm), anthropometric measurement (MUAC), and lack of ANC follow up (Table 4).

In the fully adjusted model: unplanned pregnancies $(\mathrm{AOR}=1.11$ (95\%CI: 0.80, 1.54)), experience of threatening life events $(\mathrm{AOR}=1.04 ; 95 \% \mathrm{CI} 0.70,1.54)$ ), Complication of current pregnancy ( $\mathrm{OR}=1.58$ (95\% CI: 0.98 , $2.54)$ ), and intimate partner violence (AOR $=1.10(95 \%$ CI: $0.77,1.58)$ ) during pregnancy were not associated with higher odds of low birth weight, even if there were strongly associated in bivariate analyses. No significant interaction between explanatory variables was found. A Hosmer-Lemeshow test indicated that the model fit the data well $(p=0.2865)$.

\section{Discussion}

This is the second longitudinal-population-based study examining specifically the effect of antenatal depression on birth weight in our country. The main finding was that babies of women who had antenatal depression during second and third trimester of pregnancy increased the likelihood of giving birth to LBW children in Ethiopia.

While considering all other variables constant, mothers who had antenatal depression were 2.51 $(\mathrm{COR}=2.51$ (95 CI: $1.87,3.37))$ more likely to have a child with low birth weight. This association remains significant after adjustment for unplanned pregnancies, the experience of threatening life events, a complication of current pregnancy, intimate partner violence, no ANC follow up, preterm, and MUAC $\leq 21$, showing that antenatal depression has an independent effect on low birth weight.

The association that we have reported about the increased odds of low birth weight among women with antenatal depressive symptoms did not replicate the findings of the recent cohort studies from Ethiopia by Hanlon C.et al. [43] and Fekadu D A et al. [44], which were on the impact of antenatal common mental disorders upon perinatal outcomes and the effect of antenatal depression on adverse birth outcomes respectively. These conflicting results might arise from: One, both of the previous studies reveal that the proportion of babies with LBW were $7.1 \%$ [43] and 5.25\% [44], which were less as compared to that observed in our study (27.76\%), Pakistan 29\% [68] and Nigeria14\% [69] that underpowered to detect an association between antenatal depression and low birth weight. Second, the study done by Fekadu D A et al. excluded women with a severe symptoms of depression, which underestimated the effect of antenatal depression on the risk of LBW. Third, study done by Hanlon C.et al., was specifically on impact of antenatal common mental disorders upon perinatal outcomes which includes anxiety and somatic symptoms 
Table 1 Frequency distribution of Socio-demographic factors among pregnant women at Debre Tabor and Woreta towns, Northwest Ethiopia, 2020

\begin{tabular}{|c|c|c|c|c|c|}
\hline \multirow[t]{2}{*}{ Characteristics } & \multicolumn{2}{|c|}{ Low birth weight } & \multirow{2}{*}{$\begin{array}{l}\text { Total, } \mathrm{n} \\
\text { (\%) }\end{array}$} & \multirow[t]{2}{*}{$\mathrm{X}^{2}$} & \multirow[t]{2}{*}{$P$-value } \\
\hline & Yes, n (\%) & No, $n(\%)$ & & & \\
\hline Age group & & & & 1.4879 & 0.829 \\
\hline$\leq 19$ & $7(2.70)$ & $27(4.00)$ & $34(3.64)$ & & \\
\hline $20-24$ & $69(26.64)$ & $167(24.78)$ & $236(25.29)$ & & \\
\hline $25-29$ & $113(43.63)$ & $288(42.73)$ & $401(42.98)$ & & \\
\hline $30-34$ & $49(18.92)$ & $129(19.14)$ & $178(19.08)$ & & \\
\hline$>35$ & $21(8.11)$ & $63(9.35)$ & $84(9.00)$ & & \\
\hline Religion & & & & 2.1354 & 0.344 \\
\hline Orthodox & $245(94.59)$ & $619(91.84)$ & $864(92.60)$ & & \\
\hline Muslim & $11(4.25)$ & $45(6.68)$ & $56(6.00)$ & & \\
\hline Protestant & $3(1.16)$ & $10(1.48)$ & $13(1.39)$ & & \\
\hline Ethnicity & & & & 1.1724 & 0.279 \\
\hline Amhara & $254(98.07)$ & 667 (98.96) & $921(98.71)$ & & \\
\hline Tigre & $5(1.93)$ & $7(1.04)$ & $12(1.29)$ & & \\
\hline Education & & & & 2.5674 & 0.633 \\
\hline Unable to read and write & $32(12.36)$ & $85(12.61)$ & $117(12.54)$ & & \\
\hline Able to read and write & $7(2.70)$ & $16(2.37)$ & $23(2.47)$ & & \\
\hline Primary & $78(30.12)$ & $170(25.22)$ & $248(26.58)$ & & \\
\hline High school & $66(25.48)$ & $187(27.75)$ & $253(27.12)$ & & \\
\hline Diploma and above & $76(29.34)$ & $216(32.05)$ & $292(31.30)$ & & \\
\hline Occupation & & & & 2.9230 & 0.571 \\
\hline Housewife & $133(51.35)$ & 347 (51.48) & $480(51.45)$ & & \\
\hline Employee & $71(27.41)$ & $164(24.33)$ & 235 (25.19) & & \\
\hline Merchant & 35 (13.52) & $112(16.62)$ & $147(15.76)$ & & \\
\hline Student & $8(3.09)$ & $14(2.08)$ & $22(2.36)$ & & \\
\hline Daily laborer & $12(4.63)$ & $37(5.49)$ & $49(5.25)$ & & \\
\hline Marital status & & & & 2.3080 & 0.511 \\
\hline Single & $16(6.18)$ & $31(4.60)$ & $47(5.04)$ & & \\
\hline Married & $232(89.57)$ & $624(92.58)$ & $856(91.75)$ & & \\
\hline Widowed & $5(1.93)$ & $9(1.34)$ & $14(1.50)$ & & \\
\hline Divorced & $6(2.32)$ & $10(1.48)$ & $16(1.71)$ & & \\
\hline Lack of food or Hunger & & & & 0.0276 & 0.868 \\
\hline Yes & $22(8.49)$ & $55(8.16)$ & $77(8.25)$ & & \\
\hline No & $237(91.51)$ & $619(91.84)$ & $856(91.75)$ & & \\
\hline Debt & & & & 0.4981 & 0.480 \\
\hline Yes & $29(11.20)$ & $65(9.64)$ & 94 (10.08) & & \\
\hline No & $230(88.80$ & 609 (90.36) & 839 (89.92) & & \\
\hline Wealth Index & & & & 1.1857 & 0.553 \\
\hline Low & $84(32.43)$ & $228(33.83)$ & $312(33.44)$ & & \\
\hline Middle & $82(31.66)$ & $229(33.98$ & 311 (33.33) & & \\
\hline High & $93(35.91)$ & 217 (32.19) & $310(33.23)$ & & \\
\hline
\end{tabular}


Table 2 Frequency distribution of obstetric and clinical factors among pregnant women at Debre Tabor and Woreta towns, Northwest Ethiopia, 2020

\begin{tabular}{|c|c|c|c|c|c|}
\hline \multirow[t]{2}{*}{ Characteristics } & \multicolumn{2}{|c|}{ Low birth weight } & \multirow[b]{2}{*}{ Total, n (\%) } & \multirow[t]{2}{*}{$\mathrm{x}^{2}$} & \multirow[t]{2}{*}{$P$-value } \\
\hline & Yes, n (\%) & No, $n(\%)$ & & & \\
\hline Unplanned pregnancy & & & & 3.2763 & 0.070 \\
\hline Yes & $110(42.47)$ & $243(36.05)$ & $353(37.83)$ & & \\
\hline No & $149(57.53)$ & $431(63.95)$ & $580(62.17)$ & & \\
\hline Pregnancy stage & & & & 0.7960 & 0.372 \\
\hline Second trimester & $154(59.46)$ & $379(56.23)$ & $533(57.13)$ & & \\
\hline Third trimester & $105(40.54)$ & $295(43.77)$ & $400(42.87)$ & & \\
\hline Number of live children(525) & & & & 0.4114 & 0.814 \\
\hline One & $70(49.65)$ & $181(47.14)$ & $251(47.81)$ & & \\
\hline Two-four & $68(48.23)$ & $192(50.00)$ & $260(49.52)$ & & \\
\hline Five and above & $3(2.12)$ & $11(2.86)$ & $14(2.67)$ & & \\
\hline History of current pregnancy complication & & & & 11.2571 & 0.001 \\
\hline Yes & $45(17.37)$ & $64(9.50)$ & $109(11.68)$ & & \\
\hline No & $214(82.63)$ & $610(90.50)$ & $824(88.32)$ & & \\
\hline History of abortion $(n=559)$ & & & & 1.1700 & 0.279 \\
\hline Yes & $29(19.46)$ & $64(15.61)$ & $93(16.64)$ & & \\
\hline No & $120(80.54)$ & $346(84.39)$ & $466(83.36)$ & & \\
\hline Modes of previous abortion $(n=93)$ & & & & 0.8166 & 0.366 \\
\hline Spontaneous & $25(86.21)$ & $59(92.19)$ & $84(90.32)$ & & \\
\hline Assisted & $4(13.79)$ & $5(7.81)$ & $9(9.68)$ & & \\
\hline Gravidity & & & & 2.0214 & 0.364 \\
\hline One & $110(42.47)$ & $264(39.17)$ & $374(40.09)$ & & \\
\hline Two-four & $128(49.42)$ & $366(54.30)$ & $494(52.95)$ & & \\
\hline Five and above & $21(8.11)$ & $44(6.53)$ & $65(6.97)$ & & \\
\hline Antenatal service & & & & 48.9394 & 0.000 \\
\hline Yes & $210(81.08)$ & $643(95.40)$ & $853(91.43)$ & & \\
\hline No & $49(18.92)$ & $31(4.60)$ & $80(8.57)$ & & \\
\hline Parity(544) & & & & 0.9828 & 0.612 \\
\hline One & $69(47.26)$ & $184(46.23)$ & $253(46.51)$ & & \\
\hline Two-four & $74(50.69)$ & $199(50.00)$ & $273(50.18)$ & & \\
\hline Five and above & $3(2.05)$ & $15(3.77)$ & $18(3.31)$ & & \\
\hline History of still birth $(n=559)$ & & & & 0.2995 & 0.584 \\
\hline Yes & $11(7.38)$ & $25(6.10)$ & $36(6.44)$ & & \\
\hline No & $138(92.62)$ & $385(93.90)$ & $523(93.56)$ & & \\
\hline Fear of pregnancy complication & & & & 0.1373 & 0.711 \\
\hline Yes & $138(53.28)$ & $350(51.93)$ & $488(52.30)$ & & \\
\hline No & $121(46.72)$ & $324(48.07)$ & $445(47.70)$ & & \\
\hline Chronic illness & & & & 0.5417 & 0.462 \\
\hline Yes & $16(6.18)$ & $51(7.57)$ & $67(7.18)$ & & \\
\hline No & $243(93.82)$ & $623(92.43)$ & $866(92.82)$ & & \\
\hline Twins & & & & 9.3002 & 0.002 \\
\hline Yes & $5(1.93)$ & $1(0.15)$ & $6(0.64)$ & & \\
\hline No & $254(98.07)$ & $673(99.85)$ & $927(99.36)$ & & \\
\hline
\end{tabular}


Table 2 Frequency distribution of obstetric and clinical factors among pregnant women at Debre Tabor and Woreta towns, Northwest Ethiopia, 2020 (Continued)

\begin{tabular}{|c|c|c|c|c|c|}
\hline \multirow[t]{2}{*}{ Characteristics } & \multicolumn{2}{|c|}{ Low birth weight } & \multirow[b]{2}{*}{ Total, n (\%) } & \multirow[t]{2}{*}{$x^{2}$} & \multirow[t]{2}{*}{$P$-value } \\
\hline & Yes, n (\%) & No, $n(\%)$ & & & \\
\hline \multicolumn{6}{|l|}{ Preterm } \\
\hline Yes & $63(24.32)$ & $28(4.15)$ & $91(9.75)$ & 86.4770 & 0.000 \\
\hline No & $196(75.68)$ & $646(95.85)$ & $842(90.25)$ & & \\
\hline \multicolumn{6}{|c|}{ Mid-upper arm circumference } \\
\hline$<=21$ & $70(27.03)$ & $78(11.57)$ & $148(15.86)$ & & \\
\hline$>21$ & $189(72.97)$ & $596(88.43)$ & 785 (84.14) & & \\
\hline
\end{tabular}

that is difficult to identify the independent effect of depression on birth weight and they used SRQ-20 includes several somatic items which could reflect physical symptoms of late pregnancy or physical ill-health rather than emotional distress. Moreover, the study in Butajira was studied among women with relatively economically well to do women compared to that of ours.

However, the positive effect of antenatal depression on the LBW that we have reported replicates results from the HICs [37] and LMICs [41]. Even if the exact biological mechanisms and interactions by which antenatal depression affects birth weight remain largely unknown, some research findings stated that antenatal depression stimulates the hypothalamus-pituitaryadrenal (HPA) axis leading to an increased cortisol hormone secretion specifically to the late pregnancy that restricts fetal growth [51]. In addition to this, women with antenatal depression have poor maternal dietary intake behavior and tend to consume fewer macronutrients, thereby leading to low birth weight $[49,50]$. This

Table 3 Frequency distribution of psychosocial and behavioral factors among pregnant women at Debre Tabor and Woreta towns, Northwest Ethiopia, 2020

\begin{tabular}{|c|c|c|c|c|c|}
\hline \multirow[t]{2}{*}{ Characteristics } & \multicolumn{2}{|c|}{ Low birth weight } & \multirow{2}{*}{$\begin{array}{l}\text { Total, } \mathbf{n} \\
\text { (\%) }\end{array}$} & \multirow[t]{2}{*}{$\mathrm{X}^{2}$} & \multirow[t]{2}{*}{$P$-value } \\
\hline & Yes, n (\%) & No, n (\%) & & & \\
\hline Depression & & & & 38.4173 & 0.000 \\
\hline Yes & $130(50.19)$ & $193(28.64)$ & $323(34.62)$ & & \\
\hline No & $129(49.81)$ & $481(71.36)$ & $610(65.38)$ & & \\
\hline Previous history of depression & & & & 0.1891 & 0.664 \\
\hline Yes & $74(28.57)$ & $183(27.15)$ & $257(27.55)$ & & \\
\hline No & $185(71.43)$ & $491(72.85)$ & $676(72.45)$ & & \\
\hline Family history of depression & & & & 0.0016 & 0.968 \\
\hline Yes & $36(13.90)$ & $93(13.80)$ & $129(13.83)$ & & \\
\hline No & $223(86.10)$ & $581(86.20)$ & $804(86.17)$ & & \\
\hline Life treating events & & & & 15.9697 & 0.000 \\
\hline Yes & $128(49.42)$ & $237(35.16)$ & 365 (39.12) & & \\
\hline No & $131(50.58)$ & $437(46.84)$ & $568(60.88)$ & & \\
\hline Social support & & & & 1.1504 & 0.563 \\
\hline Poor & $117(45.17)$ & $299(44.36)$ & $416(44.59)$ & & \\
\hline Moderate & $92(35.52)$ & $224(33.24)$ & $316(33.87)$ & & \\
\hline Strong & $50(19.31)$ & $151(22.40)$ & $201(21.54)$ & & \\
\hline Intimate partner violence & & & & 17.1062 & 0.000 \\
\hline Yes & $164(63.32)$ & $325(48.22)$ & 489 (52.41) & & \\
\hline No & 95 (36.68) & 349 (51.78) & 444 (47.59) & & \\
\hline Alcohol use & & & & 0.4520 & 0.501 \\
\hline Yes & $61(23.55)$ & 145 (21.51) & 206 (22.08) & & \\
\hline No & $198(76.45)$ & $529(78.49)$ & 727 (77.92) & & \\
\hline
\end{tabular}


Table 4 Bivariate and multivariable analysis for obstetric, clinical, and psychological factors among babies born alive at Debre Tabor and Woreta towns, Northwest Ethiopia, 2020

\begin{tabular}{|c|c|c|c|c|c|}
\hline \multirow[t]{2}{*}{ Characteristics } & \multicolumn{2}{|c|}{ LBW } & \multirow[t]{2}{*}{ COR at $95 \% \mathrm{Cl}$} & \multirow[t]{2}{*}{ AOR at $95 \% \mathrm{C}$} & \multirow[t]{2}{*}{$P$-value } \\
\hline & Yes & No & & & \\
\hline Depression & & & & & 0.001 \\
\hline Yes & 130 & 193 & $2.51(1.87,3.37)$ & $1.92(1.31,2.81)^{*}$ & \\
\hline No & 129 & 481 & 1 & 1 & \\
\hline Complication of current pregnancy & & & & & 0.059 \\
\hline Yes & 45 & 64 & $2.00(1.33,3.03)$ & $1.58(.98,2.54)$ & \\
\hline No & 214 & 610 & 1 & 1 & \\
\hline Lack ANC follow up & & & & & 0.000 \\
\hline Yes & 49 & 31 & $4.84(3.01,7.79)$ & $3.91(2.32,6.59)^{* *}$ & \\
\hline No & 210 & 643 & 1 & 1 & \\
\hline Life threatening events & & & & & 0.844 \\
\hline Yes & 128 & 237 & $1.80(1.35,2.41)$ & $1.04(.70,1.54)$ & \\
\hline No & 131 & 437 & 1 & 1 & \\
\hline Mid upper arm circumference & & & & & 0.000 \\
\hline$<=21$ & 70 & 78 & $2.83(1.97,4.06)$ & $2.39(1.60,3.59)^{* *}$ & \\
\hline$>21$ & 189 & 596 & 1 & 1 & \\
\hline Intimate partner violence & & & & & 0.586 \\
\hline Yes & 164 & 325 & $1.85(1.38,2.49)$ & $1.10(.77,1.58)$ & \\
\hline No & 95 & 349 & 1 & 1 & \\
\hline Preterm & & & & & 0.000 \\
\hline Yes & 63 & 28 & $7.42(4.62,11.90)$ & $6.68(4.03,11.08)^{* *}$ & \\
\hline No & 196 & 646 & 1 & 1 & \\
\hline Unplanned pregnancy & & & & & 0.528 \\
\hline Yes & 110 & 243 & $1.31(.98,1.75)$ & $1.11(.80,1.54)$ & \\
\hline No & 149 & 431 & 1 & 1 & \\
\hline
\end{tabular}

collective mechanism speculates that antenatal depression plays an important role in the causation of intrauterine growth retardation and low birth weight, which in turn may lead to impaired mental development in infanthood and mental disorders later in life [70].

According to the EDHS report, the proportion of babies with LBW in our sample (27.76\%) was double the estimated national average of LBW for Ethiopia [29]. These national estimates of LBW were largely derived from health facility data that cannot address babies born at home, which is likely to have led to an underestimation of underweight babies. Our prevalence estimate is similar to one of the few other community-based studies (28.3\%) from Ethiopia [71].

It is well known that poor maternal nutritional status is the principal cause of LBW in low-income countries [72]. Mothers with MUAC less than $\leq 21 \mathrm{~cm}$ were two times more likely to give birth of low weight baby than mothers whose MUAC was more than 21. This result is congruent with studies conducted in other low-income countries [71, 73]. It may be speculated that LBW is associated with situations with uterine malnutrition due to alterations in placental circulation [72] and poor bioavailability of specific micronutrients such as oral vitamin B12 intake, possibly limiting fetal growth [74].

Antenatal care follow-up is essential for early identification and treatment of pregnancy-induced complications that lead to low birth weight newborns. Although we did not address the time of the first visit in this study, literature indicated that improving coverage of mental programs and early starting in ANC visit play a great role in improved birth weight $[75,76]$.

The odds of lack of ANC follow up among mothers who delivered LBW babies is about four times higher than those who had normal weight babies. The result is similar to those reported by other studies [31, 71]. Pregnant women who had no ANC follow-up, unable to early detect and treat pregnancy-induced complications that leads to LBW and may not receive routinely provision nutritional and lifestyle counseling during 
ANC visits that leads to better growth and development of the fetus [77].

This study also revealed that preterm neonates were significantly associated with LBW. Neonates delivered before 37 weeks of gestational age were more than six times more likely to have LBW as compared to term neonates. This study's result is in line with the study conducted in Kenya [78],Tanzania [79], and other studies in Ethiopia Jimma [80] Gondar [81]. This might be as a result of intrauterine growth retardation and decreased skeletal muscle mass and subcutaneous fat tissue because of prematurity $[76,82]$.

\section{Limitations of the study}

Our finding could be interpreted in the presence of some limitations. This study did not address the mechanisms by which antenatal depression affects the fetus. Evidence indicated that the effect of antenatal depression had been mediated by elevated antenatal depression norepinephrin levels [83]. Besides, we had no information on antidepressant medication for those referred to a psychiatric unit, thus could not assess their roles as a confounder in multivariable analysis. In addition to these, lack of data related to pre-pregnancy weight, dietary intake and preconception care is the limitation of this study.

\section{Conclusion}

This population-based follow-up study found an independent association between antenatal depression in the second and third trimester of pregnancy and LBW in a sample of Ethiopian infants. Therefore antenatal depression has serious fetal consequences; early identification of depressive symptoms using the EPDS and treatment of antenatal depression could benefit not only maternal mental health but also the physical health, growth, and development of the fetus.

\section{Abbreviations \\ ANC: Ante Natal Care; AOR: Adjusted Odds Ratio „ Cl: Confidence Interval; COR: Crude odds ratio; OR: Odds Ratio; CM: Common Mental Disorder; EPDS: Edinburgh Postnatal Depression Scale; FAST: Fast Alcohol Screening Test; IPV: Intimate Partner Violence; LTE: List of Threatening Experiences; OSSS-3: Oslo-3 Social Support Scale; LBW: Low Birth Weight; MUAC: Mid Upper Arm Circumference}

\section{Acknowledgments}

The authors acknowledge the University of Gondar for providing financial support. We are grateful to the women who participated in the study. Our special thanks goes to data collectors and supervisors.

\section{Provenance and peer-reviewed}

Not commissioned, externally peer-reviewed.

\section{Authors' contributions}

All authors designed and developed the research protocol and tool, and were responsible for training and data collection. They analyzed the data, interpreted the findings, and wrote the manuscript. Finally, all authors read and approved the revised manuscript.

\section{Funding}

This study was conducted as part of Ph.D. degree fulfillment funded by the University of Gondar.

\section{Availability of data and materials}

The datasets supporting the conclusions of this article are available upon request to the corresponding author. Data were not publicly available to protect participant confidentiality.

\section{Declarations}

\section{Ethics approval and consent to participate}

This study was approved by the University of Gondar Ethical Review Board and the Regional research office. We received permission from the Debre Tabor and Woreta towns' health department and administration office. Written informed consent and assent was obtained from each participant.

\section{Consent for publication}

Not applicable.

\section{Competing interests}

The authors declare that they have no competing interests.

\section{Author details}

${ }^{1}$ Department of Psychiatry, College of Health Sciences, Debre Tabor University, Debre Tabor, Ethiopia. ${ }^{2}$ Department of Epidemiology and Biostatistics, College of Medicine and Health Sciences, University of Gondar, Gondar, Ethiopia. ${ }^{3}$ Department of Health Education and Behavioral Sciences, College of Medicine and Health Sciences, University of Gondar, Gondar, Ethiopia.

Received: 6 January 2021 Accepted: 17 June 2021

Published online: 05 July 2021

\section{References}

1. https://www.lawinsider.com/dictionary/antenatal-period.

2. Evans J, Heron J, Francomb H, Oke S, Golding J. Cohort study of depressed mood during pregnancy and after childbirth. Bmj. 2001;323(7307):257-60.

3. Fatoye FO, Adeyemi AB, Oladimeji BY. Emotional distress and its correlates among Nigerian women in late pregnancy. J Obstet Gynaecol. 2004;24(5): 504-9.

4. Demyttenaere $K$, Lenaerts $H$, Nijs P, Van Assche FA. Individual coping style and psychological attitudes during pregnancy predict depression levels during pregnancy and during postpartum. Acta Psychiatr Scand. 1995;91(2): 95-102.

5. Goebert D, Morland L, Frattarelli L, Onoye J, Matsu C. Mental health during pregnancy: a study comparing Asian, Caucasian and native Hawaiian women. Matern Child Health J. 2007;11(3):249-55.

6. Jafri SAM, Ali M, Ali R, Shaikh S, Abid M, Aamir IS. Prevalence of depression among pregnant women attending antenatal clinics in Pakistan. Acta Psychopathol. 2017;3(5):54.

7. Shah SMA, Bowen A, Afridi I, Nowshad G, Muhajarine N. Prevalence of antenatal depression: comparison between Pakistani and Canadian women. JPMA. 2011;61(3):242.

8. Organization WH. Maternal mental health and child health and development in resource-constrained settings: report of a UNFPA: World Health Organization; 2009.

9. Bisetegn TA, Mihretie G, Muche T. Prevalence and predictors of depression among pregnant women. PLoS One. 2016;11(9).

10. Sahile MA, Segni MT, Awoke T, Bekele D. Prevalence and predictors of antenatal depressive symptoms among women attending Adama hospital antenatal clinic, Adama, Ethiopia. Int J Nurs Midwife. 2017;9(5):58-64.

11. Alder J, Fink N, Bitzer J, Hösli I, Holzgreve W. Depression and anxiety during pregnancy: a risk factor for obstetric, fetal and neonatal outcome? A critical review of the literature. J Matern Fetal Neonatal Med. 2007;20(3):189-209.

12. Norbeck JS, Tilden VP. Life stress, social support, and emotional disequilibrium in complications of pregnancy: a prospective, multivariate study. J Health Soc Behav. 1983:30-46.

13. Kahn RS, Certain L, Whitaker RC. A reexamination of smoking before, during, and after pregnancy. Am J Public Health. 2002;92(11):1801-8. 
14. Murray $L$, Cooper $P$, Hipwell A. Mental health of parents caring for infants. Arch Womens Mental Health. 2003;6(2):s71-s7.

15. Hanna EZ, Faden VB, Dufour MC. The motivational correlates of drinking, smoking, and illicit drug use during pregnancy. J Subst Abus. 1994;6(2):155-67.

16. Bonari L, Bennett $H$, Einarson A, Koren G. Risks of untreated depression during pregnancy. Can Fam Physician. 2004;50(1):37-9.

17. Lutsiv O, McKinney B, Foster G, Taylor V, Pullenayegum E, McDonald S. Pregnancy complications associated with the co-prevalence of excess maternal weight and depression. Int J Obes. 2015;39(12):1710-6.

18. Spirito A, Ruggiero L, Coustan D, McGarvey S, Bond A. Mood state of women with diabetes during pregnancy. J Reprod Infant Psychol. 1992;10(1):29-38.

19. Chung TKH, Lau K, Yip ASK, Chiu HFK, DTS L. Antepartum depressive symptomatology is associated with adverse obstetric and neonatal outcomes. Psychosom Med. 2001;63(5):830-4.

20. Bitew T, Hanlon C, Kebede E, Honikman S, Fekadu A. Antenatal depressive symptoms and perinatal complications: a prospective study in rural Ethiopia. BMC Psychiatry. 2017;17(1):301

21. Rahman A, Bunn J, Lovel H, Creed F. Association between antenatal depression and low birthweight in a developing country. Acta Psychiatr Scand. 2007;115(6):481-6.

22. Grigoriadis S, VonderPorten EH, Mamisashvili L, Tomlinson G, Dennis C-L, Koren $\mathrm{G}$, et al. The impact of maternal depression during pregnancy on perinatal outcomes: a systematic review and meta-analysis. J Clin Psychiatry. 2013;74(4):321-41.

23. Marcus SM. Depression during pregnancy: rates, risks and consequences. J Popul Ther Clin Pharmacol. 2009;16(1).

24. Zerbeto AB, Cortelo FM, Élio FB. Association between gestational age and birth weight on the language development of Brazilian children: a systematic review. J Pediatr (Versão em Português). 2015;91(4):326-32.

25. Badshah S, Mason L, McKelvie K, Payne R, Lisboa PJ. Risk factors for low birthweight in the public-hospitals at Peshawar, NWFP-Pakistan. BMC Public Health. 2008;8(1):197

26. Organization WH. Organization WH: Global Nutrition Targets 2025: Low birth weight policy brief. Global Nutr Targets. 2014;2015:2025.

27. Organization WH. UNICEF-WHO low birthweight estimates: levels and trends 2000-2015: World Health Organization; 2019.

28. Macro: CSAaO. Ethiopia demographic and health survey 2011. Addis Ababa: Central Statistical Agency and ORC Macro; 2011.

29. Macro: CSAaO. Ethiopia demographic and health survey 2016. Addis Ababa: Central Statistical Agency and ORC Macro; 2016.

30. Dilnessa T, Belete E, Tefera M. Prevalence of low birth Weight and associated factors among new born babies in Ataye primary hospital, north Shoa, Ethiopia. Asian J Med Health. 2018;2020:1-11.

31. Alemu T, Umeta M. Prevalence and predictors of" small size" babies in Ethiopia: in-depth analysis of the Ethiopian demographic and health survey, 2011. Ethiop J Health Sci. 2016;26(3):243-50.

32. Sisay MM, Muche AA. Spatial distribution and factors associated with low birth weight in Ethiopia using data from Ethiopian demographic and health survey 2016: spatial and multilevel analysis. bioRxiv. 2020.

33. Desta M, Tadese M, Kassie B, Gedefaw M. Determinants and adverse perinatal outcomes of low birth weight newborns delivered in Hawassa University comprehensive specialized hospital, Ethiopia: a cohort study. BMC Res Notes. 2019;12(1):118

34. Kahsay AH, Abebe HT, Gebretsadik LG, Tekle TH. Survival and predictors of early neonatal death in neonatal intensive care unit of Mekelle general and Ayder comprehensive specialized hospitals, northern Ethiopia, 2018: prospective cohort study; 2019.

35. Woldehanna T, Idejene E. Neonatal mortality in a teaching hospital, North Western Ethiopia. Central Afr J Med. 2005:51(3-4):30-3.

36. Eastwood J, Ogbo FA, Hendry A, Noble J, Page A, Group EYR. The impact of antenatal depression on perinatal outcomes in Australian women. PLoS One. 2017;12(1):e0169907.

37. Räisänen S, Lehto SM, Nielsen HS, Gissler M, Kramer MR, Heinonen S. Risk factors for and perinatal outcomes of major depression during pregnancy: a population-based analysis during 2002-2010 in Finland. BMJ Open. 2014; $4(11)$

38. Grote NK, Bridge JA, Gavin AR, Melville JL, lyengar S, Katon WJ. A metaanalysis of depression during pregnancy and the risk of preterm birth, low birth weight, and intrauterine growth restriction. Arch Gen Psychiatry. 2010; 67(10):1012-24.
39. Jarde A, Morais M, Kingston D, Giallo R, MacQueen GM, Giglia L, et al. Neonatal outcomes in women with untreated antenatal depression compared with women without depression: a systematic review and metaanalysis. JAMA Psychiatry. 2016;73(8):826-37.

40. Patel V, Prince M. Maternal psychological morbidity and low birth weight in India. Br J Psychiatry. 2006;188(3):284-5.

41. Li X, Gao R, Dai X, Liu H, Zhang J, Liu X, et al. The association between symptoms of depression during pregnancy and low birth weight: a prospective study. BMC Pregnancy Childbirth. 2020;20(1):1-7.

42. Nasreen HE, Pasi HB, Rifin SM, Aris MAM, Ab Rahman J, Rus RM, et al. Impact of maternal antepartum depressive and anxiety symptoms on birth outcomes and mode of delivery: a prospective cohort study in east and west coasts of Malaysia. BMC Pregnancy Childbirth. 2019;19(1):201.

43. Hanlon C, Medhin G, Alem A, Tesfaye F, Lakew Z, Worku B, et al. Impact of antenatal common mental disorders upon perinatal outcomes in Ethiopia: the P-MaMiE population-based cohort study. Tropical Med Int Health. 2009; 14(2):156-66.

44. Fekadu Dadi A, Miller ER, Woodman RJ, Azale T, Mwanri L. Effect of antenatal depression on adverse birth outcomes in Gondar town, Ethiopia: a community-based cohort study. PLoS One. 2020;15(6):e0234728.

45. Bitew T, Hanlon C, Kebede E, Medhin G, Fekadu A. Antenatal depressive symptoms and maternal health care utilisation: a population-based study of pregnant women in Ethiopia. BMC Pregnancy Childbirth. 2016;16(1):301.

46. Tefera TB, Erena AN, Kuti KA, Hussen MA. Perinatal depression and associated factors among reproductive aged group women at Goba and Robe Town of Bale Zone, Oromia Region, South East Ethiopia. Matern Health Neonatol Perinatol. 2015;1(1):12.

47. Excellence NIfC. Depression in adults: recognition and management. NICE guideline (CG 90). Retreived from https://www.nice.org.uk/guidance/cg90. 2009

48. Barker ED, Kirkham N, Ng J, Jensen SK. Prenatal maternal depression symptoms and nutrition, and child cognitive function. Br J Psychiatry. 2013; 203(6):417-21.

49. Payab M, ARD M, Eshraghian M, Rostami R, Siassi F, Ahmadi M, et al. The association between depression, socio-economic factors and dietary intake in mothers having primary school children living in Rey, South of Tehran, Iran. J Diabetes Metab Disord. 2012;11(1):26.

50. Saeed A, Raana T, Saeed AM, Humayun A. Effect of antenatal depression on maternal dietary intake and neonatal outcome: a prospective cohort. Nutr J. 2015;15(1):64.

51. Diego MA, Field T, Hernandez-Reif M, Schanberg S, Kuhn C, GonzalezQuintero VH. Prenatal depression restricts fetal growth. Early Hum Dev. 2009;85(1):65-70.

52. Zimmer-Gembeck MJ, Helfand M. Low birthweight in a public prenatal care program: behavioral and psychosocial risk factors and psychosocial intervention. Soc Sci Med. 1996:43(2):187-97.

53. DDHO. Debetabor District Health Office annual report on maternal and child health service performance. 2018.

54. Tesfaye M, Hanlon C, Wondimagegn D, Alem A. Detecting postnatal common mental disorders in Addis Ababa, Ethiopia: validation of the Edinburgh postnatal depression scale and Kessler scales. J Affect Disord. 2010;122(1-2):102-8.

55. Cox JL, Holden JM, Sagovsky R. Detection of postnatal depression: development of the 10-item Edinburgh postnatal depression scale. $\mathrm{Br}$ J Psychiatry. 1987;150(6):782-6.

56. Brugha TS, Cragg D. The list of threatening experiences: the reliability and validity of a brief life events questionnaire. Acta Psychiatr Scand. 1990;82(1): 77-81.

57. Montón-Franco C, Josefa G, Gómez-Barragán M, Sánchez-Celaya M, Ángel Díaz Barreiros $M$.

PsychometricpropertiesoftheListofThreateningExperiences-LTE anditsassociationwith psychosocialfactorsandmentaldisordersaccordingtodifferentscoringmethods. Affect Disord. 2013;150:931-40.

58. DalgardOS DC, Lehtinen V, Vazquez-Barquero JL, Casey P. Negativelifeevents, socialsupport and gender difference in depression: amultinational community survey with data from the ODINstudy. Soc Psychiatry Psychiatr Epidemiol. 2006;41:444-51.

59. Boen $\mathrm{H}$, Dalgard OS, Bjertness E. The importance of social support in the a ssociations between psychological distress and somatic health problems and socio-economic factors among older adults living at home: a crosssectional study. BMC Geriatr. 2012;12. 
60. FekaduA MG, SelamuM HM, AlemA. Populationlevel mentaldistress inruralEthiopia. BMCPsychiatry. 2014;14:194.

61. Rasch V, Van TN, Nguyen HTT, Manongi R, Mushi D, Meyrowitsch DW, et al. Intimate partner violence (IPV): the validity of an IPV screening instrument utilized among pregnant women in Tanzania and Vietnam. PLoS One. 2018; 13(2):e0190856.

62. Wang H, Bhutta ZA, Coates MM, Coggeshall M, Dandona L, Diallo K, et al. Global, regional, national, and selected subnational levels of stillbirths, neonatal, infant, and under-5 mortality, 1980-2015: a systematic analysis for the global burden of disease study 2015. Lancet. 2016;388(10053):1725-74.

63. Hodgson R, Alwyn T, John B, Thom B, Smith A. The FAST alcohol screening test. Alcohol Alcohol. 2002;37(1):61-6.

64. Organization WH. Physical status: the use of and interpretation of anthropometry, report of a WHO expert committee: World Health Organization; 1995.

65. M-t V, Antierens A, Sackl A, Staderini N, Captier V. Which anthropometric indicators identify a pregnant woman as acutely malnourished and predict adverse birth outcomes in the humanitarian context? PLoS Curr. 2013;5.

66. Fewtrell MS, Kennedy K, Singhal A, Martin RM, Ness A, Hadders-Algra M, et al. How much loss to follow-up is acceptable in long-term randomised trials and prospective studies? Arch Dis Child. 2008;93(6):458-61.

67. V K, M M, P C. Loss to follow-up in cohort studies: how much is too much? Eur J Epidemiol. 2004;19(8):751-60.

68. Jamshed S, Farah-Khan AB, Ali BB, Akram Z, Ariff M. Frequency of low birth weight and its relationship with maternal nutritional and dietary factors: a cross-sectional study. Cureus. 2020;12(6)

69. Ndu IK, Edelu BO, Uwaezuoke SN, Chinawa JC, Ubesie A, Ogoke CC, et al. J Neonatal Biol. 2015;101:0.88-2.08.

70. Gale CR, Martyn CN. Birth weight and later risk of depression in a national birth cohort. Br J Psychiatry. 2004;184(1):28-33.

71. Assefa N, Berhane Y, Worku A. Wealth status, mid upper arm circumference (MUAC) and antenatal care (ANC) are determinants for low birth weight in Kersa, Ethiopia. PloS One. 2012;7(6):e39957.

72. Bale JR, Stoll BJ, Lucas AO. Reducing maternal mortality and morbidity. Improving birth outcomes: meeting the challenge in the developing world: National Academies Press (US); 2003.

73. Adane T, Dachew BA. Low birth weight and associated factors among singleton neonates born at Felege Hiwot referral hospital, north West Ethiopia. Afr Health Sci. 2018;18(4):1204-13.

74. Muthayya S. Maternal nutrition \& low birth weight-what is really important. Indian J Med Res. 2009;130(5):600-8.

75. Gebremariam A. Factors predisposing to low birth weight in Jimma hospital south western Ethiopia. East Afr Med J. 2005;82(11):554.

76. Ramakrishnan U. Nutrition and low birth weight: from research to practice. Am J Clin Nutr. 2004;79(1):17-21.

77. Weight LB. A tabulation of available information. Maternal Health and Safe Motherhood Programme. Geneva: World Health Organization and UNICEF; 1992

78. Muchemi OM, Echoka E, Makokha A. Factors associated with low birth weight among neonates born at Olkalou District Hospital, Central Region, Kenya. Pan Afr Med J. 2015;20(1).

79. Siza J. Risk factors associated with low birth weight of neonates among pregnant women attending a referral hospital in northern Tanzania. Tanzan J Health Res. 2008;10(1):1-8.

80. Tema T. Prevalence and determinants of low birth weight in Jimma zone, Southwest Ethiopia. East Afr Med J. 2006;83(7):366.

81. Teshome D, Telahun T, Solomon D, Abdulhamid I. A study on birth weight in a teaching-referral hospital, Gondar, Ethiopia. Central Afr J Med. 2006; 52(1-2):8-11.

82. Barton L, Hodgman JE, Pavlova Z. Causes of death in the extremely low birth weight infant. Pediatrics. 1999;103(2):446-51.

83. Glover V. Mechanisms by which maternal mood in pregnancy may affect the fetus. Contemp Rev Obstet Gynecol. 1999;11:155-60.

\section{Publisher's Note}

Springer Nature remains neutral with regard to jurisdictional claims in published maps and institutional affiliations.

\section{Ready to submit your research? Choose BMC and benefit from:}

- fast, convenient online submission

- thorough peer review by experienced researchers in your field

- rapid publication on acceptance

- support for research data, including large and complex data types

- gold Open Access which fosters wider collaboration and increased citations

- maximum visibility for your research: over $100 \mathrm{M}$ website views per year

At BMC, research is always in progress.

Learn more biomedcentral.com/submissions 